\title{
Modelling comparison to evaluate the importance of phenology for the effects of climate change on growth of temperate-zone deciduous trees
}

\author{
Koen Kramer \\ Institute for Forestry and Nature Research (IBN-DLO), PO Box 23,6700 AA Wageningen. The Netherlands
}

\begin{abstract}
The importance of 3 phenological types of deciduous trees for the effects of climate change on growth was evaluated using the model FORGRO. The climate change scenarios used were a doubling of the $\mathrm{CO}_{2}$ concentration $\left(700 \mu \mathrm{mol} \mathrm{mol}^{-1}\right)$ and an increase in temperature ranging from 0 to $7^{\circ} \mathrm{C}$. To elucidate the relative importance of photosynthesis and allocation for this evaluation, models with different levels of mechanistic detail of photosynthesis and allocation were used. The photosynthesis approach of FORGRO was compared to the Farquhar \& von Caemmerer approach as formulated in PGEN (FORGRO-PGEN). Similarly, the allocation approach of FORGRO was compared to the transport-resistance approach, as formulated in the ITE-Edinburgh model (ITE-FORGRO). A sensitivity analysis was performed to ascertain whether the response of gross photosynthesis to a climate change scenario depends on the value assigned to parameters in these models, and to compare this sensitivity with the differences found between the phenological types. The differences in the response of gross photosynthesis $\left(P_{\mathrm{g}}\right)$ to the climate change scenarios between the phenological types were smaller accoraing to TIE-FORCKU as compared to FORGRO. These differences are of a similar magnitude when comparing the 2 photosynthesis models. Furthermore, FORGRO-PGEN showed that the response of $P_{\mathrm{g}}$ to a $2 \times\left[\mathrm{CO}_{2}\right]$ increases with rising temperature, thus compensating for the increase in respiration. For both FORGRO and ITE-FORGRO this $\mathrm{CO}_{2}$ and temperature interaction was not found. Consequently, in these models the increase in respiration exceeded the increase in gross photosynthesis at the higher range of temperature rise. The sensitivity analysis showed that the models differ in the sensitivity of the response of $P_{\mathrm{y}}$ to a $2 \times\left[\mathrm{CO}_{2}\right]$ scenario combined with a temperature rise of $2^{\circ} \mathrm{C}\left(C_{700} / T_{2}\right)$, when parameter values change by $\pm 25 \%$. In FORGRO-PGEN, the magnitude of the response of $P_{\mathrm{g}}$ depended on the values of some of its parameters, especially those determining the Michaelis-Menten kinetics of Rubisco, which for these parameters exceeded the differences between the phenological types in this scenario. In both FORGRO and ITE-FORGRO this sensitivity is similar to or less than the difference between the phenological types in the $C_{700} / T_{2}$ scenario.
\end{abstract}

KEY WORDS: Climate change - Deciduous trees Growth - Models P Phenology

\section{INTRODUCTION}

As a result of natural selection, the annual biological cycle of the growth and dormancy of trees is synchronized to the annual climatic cycle of light, temperature and precipitation, thus determining growth. If the climate changes within the life-span of a tree, this synchronization may be partly lost. Consequently, either a part of the growing period of a tree may occur when the climate is not favourable for growth, or the growing period may not fully exploit the period when the climate is favourable for growth. On the other hand, the species may be able to adjust by phenotypic plasticity. Earlier studies have predicted that, based on climate change scenarios, the probability of spring frost damage is likely to decrease in temperate zone Europe (Kramer 1994, Murray et al. 1989). It has also been found that trees do possess a considerable plasticity to accommodate a change in their local environment phenotypically (Kramer 1995). The aim of the study reported in this paper was to evaluate the importance of differences in phenological response to 
temperature for the effects of climate change on the growth of deciduous, temperate-zone tree species Two models of photosynthesis and 2 models of allocation were compared, to elucidate the consequences of describing these processes with different levels of mechanistic detail.

In an earlier study 3 phenological patterns induced by a structural rise in temperature were found: (1) a similar advance of both leaf unfolding and leaf fall; (2) an advance of leaf unfolding, but no change in leaf fall; and (3) a larger advance of leaf fall than leaf unfolding (Kramer 1995). These 3 phenological types correspond to Betula, Fagus, and Quercus, respectively.

Models incorporating detailed descriptions of light interception, photosynthesis, respiration and allocation are required to evaluate the effects of climate change on growth of deciduous trees. The models compared in this study were: (1) FORGRO (Mohren 1987, 1994) using the descriptions of photosynthesis of Goudriaan et al. (1985) and fixed keys for allocation; (2) FORGRO coupled to PGEN (Friend 1993), substituting the biochemical photosynthesis model of Farquhar \& von Caemmerer (1982) for the photosynthesis model; and (3) FORGRO coupled to the ITE-Edinburgh model (Thornley 1991), in which the allocation keys of FORGRO are replaced by the transport-resistance approach of partitioning.

Two aspects of climate change and growth of deciduous trees were studied through model comparison: (1) the consequences of the phenological types on the effects of climate change scenarios on gross photosynthesis, and (2) the sensitivity of the scenario-induced response of gross photosynthesis to a change in parameter values of the models.

\section{MATERIALS AND METHODS}

Phenology. To avoid inaccuracies in the date of both leaf unfolding and leaf fall in the analysis of the species response to the different scenarios, historical phenological observations for a 14 yr period were used. Phenological observations of Betula pubescens (birch), Fagus sylvatica (beech) and Quercus robur (oak) in The Netherlands were available for every year from 1940 until 1953, except for 1945. For 1945 the average value of the phenological events was used. The phenological events monitored were leaf unfolding, full leaf and leaf fall. The observers had been provided with detailed instructions for each species, including pictures, of the exact event to observe, and instructions on how to select the trees (Anonymous 1950). The shifts of these events with either mean winter or summer temperature, based on an extensive data set containing phenological observations of clones relocated over a large latitudinal throughout Europe (Kramer 1995), are presented in Table 1. When the temperature was increased according to a scenario, the observed dates of leaf unfolding, full leaf and leaf fall were adjusted according to the known responses of Betula, Fagus and Quercus (Table 1). The shift in full leaf with winter temperature was assumed to be similar to leaf unfolding

Scenarios. Daily meteorological measurements for the period 1940 to 1953 were available for De Bilt $\left(52^{\circ} \mathrm{N}, 6^{\circ} \mathrm{E}\right)$, located in the centre of The Netherlands, and used as input to the models. In all calculations, this series was adjusted according to a scenario. The variable evaluated was the annual rate of gross photosynthesis, $P_{\mathrm{g}}\left(\mathrm{t} \mathrm{CH}_{2} \mathrm{O} \mathrm{ha}^{-1} \mathrm{yr}^{-1}\right)$, averaged over the simulation period.

To evaluate the importance of phenology, the $\mathrm{CO}_{2}$ concentration was set at $700 \mu \mathrm{mol} \mathrm{mol} \mathrm{m}^{-1}$, and the temperature was increased unitormly by a maximum of $7{ }^{\circ} \mathrm{C}$ in steps of $1^{\circ} \mathrm{C}$. The benchmark scenario (no change in temperature) was also examined. The response for $P_{\mathrm{g}}$ of Betula, Fagus and Quercus to these scenarios was calculated according to the 3 models. The results were expressed relative to the scenario with $\left[\mathrm{CO}_{2}\right]=$ $350 \mu \mathrm{mol} \mathrm{mol}{ }^{-1}$, without an increase in temperature.

The sensitivity of the response of $P_{\mathrm{g}}$ to a change of $\pm 25 \%$ in parameter value was evaluated by comparing the response to the scenario with $\left[\mathrm{CO}_{2}\right]=700 \mu \mathrm{mol}$ $\mathrm{mol}^{-1}$ and a uniform $2^{\circ} \mathrm{C}$ rise in temperature with the reference scenario with $\left.\mathrm{CO}_{2}\right]=350 \mu \mathrm{mol} \mathrm{mol}{ }^{-1}$ and no increase in temperature. These scenarios will be referred to as $C_{700} / T_{2}$ and $C_{350} / T_{0}$, respectively. The phenology of Betula (Table 1) was used for this analysis.

Table 1. Phenological characteristics of Betula, Fagus and Quercus. $U$ : average date of leaf unfolding: $G$ : date of the stage full leaf $F$ : date of leaf $\mathrm{fall}_{;} \delta U / \delta T_{\mathrm{w}}$ : change in date of leaf unfolding with mean winter temperature $\left(T_{w}, 1\right.$ November until leaf unfolding); $\delta G / \delta T_{\mathrm{w}}$ : change in date of full leaf; $\delta F / \delta T_{s}$ : change in date of leaf fall with mean summer temperature $\left(T_{\mathrm{s}}, 1 \mathrm{May}\right.$ until leaf fall). $I$ : average cumulative irradiance from date of leaf unfolding to date of leaf fall, in The Netherlands $\left(\mathrm{MJ} \mathrm{m}^{-2}\right.$ growing season $\left.{ }^{-1}\right) ; \delta I_{U} / \delta T_{\mathrm{w}}$ : change in $I$ caused by advancement of leaf unfolding $\left(\mathrm{MJ}{ }^{\circ} \mathrm{C}^{-1}\right) ; \delta I_{F} / \delta I_{\mathrm{s}}$ : change in $I$ caused by advancement of leaf fall $\left(\mathrm{MJ}^{\circ} \mathrm{C}^{-1}\right)$

\begin{tabular}{|lccc|}
\hline & Betula & Fagus & Quercus \\
\hline$U$ & 22 April & 1 May & 5 May \\
$G$ & 2 May & 8 May & 15 May \\
$F$ & 4 October & 16 October & 20 October \\
$I$ & 2504 & 2468 & 2413 \\
$\delta U / \delta T_{w}$ & -3 & -2 & -2 \\
$\delta G / \delta T_{w}$ & -3 & -2 & -2 \\
$\delta I_{U} / \delta T_{w}$ & $44(1.8 \%)$ & $28(1.1 \%)$ & $32(1.3 \%)$ \\
$\delta F / \delta T_{\mathrm{s}}$ & -3 & 0 & -5 \\
$\delta I_{F} / \delta T_{\mathrm{s}}$ & $-24(-1.0 \%)$ & $0(0 \%)$ & $-28(-1.1 \%)$ \\
& & & \\
\hline
\end{tabular}


Models. Three models with different levels of detail of photosynthesis and allocation were used, i.e. FORGRO, PGEN and the ITE-Edinburgh model. Briefly, FORGRO (Mohren 1987, 1994) is a process-based model suitable for predicting the growth of an even-aged monoculture of coniferous tree species. The photosynthesislight response curve is modelled using a negative exponential function. An increase in the external $\mathrm{CO}_{2}$ concentration alters both the initial light use efficiency and the $\mathrm{CO}_{2}$-limited rate of gross photosynthesis (Goudriaan et al. 1985). Allocation of assimilates is modelled using fixed allocation keys. PGEN (Friend 1993) is a model aiming to predict the rate of photosynthesis at the biochemical level (Farquhar \& von Caemmerer 1982), and the optimization of stomatal conductance given a set of environmental and biological parameters. The ITE-Edinburgh model (Thornley 1991) is a transport-resistance model of forest growth and partitioning based on counter-gradients of carbon and nitrogen substrate between foliage and roots. In the foregoing account the processes in which the models differ and those parts which were adjusted to calculate the growth of deciduous trees have been emphasized: see also Appendices $1 \& 2$.

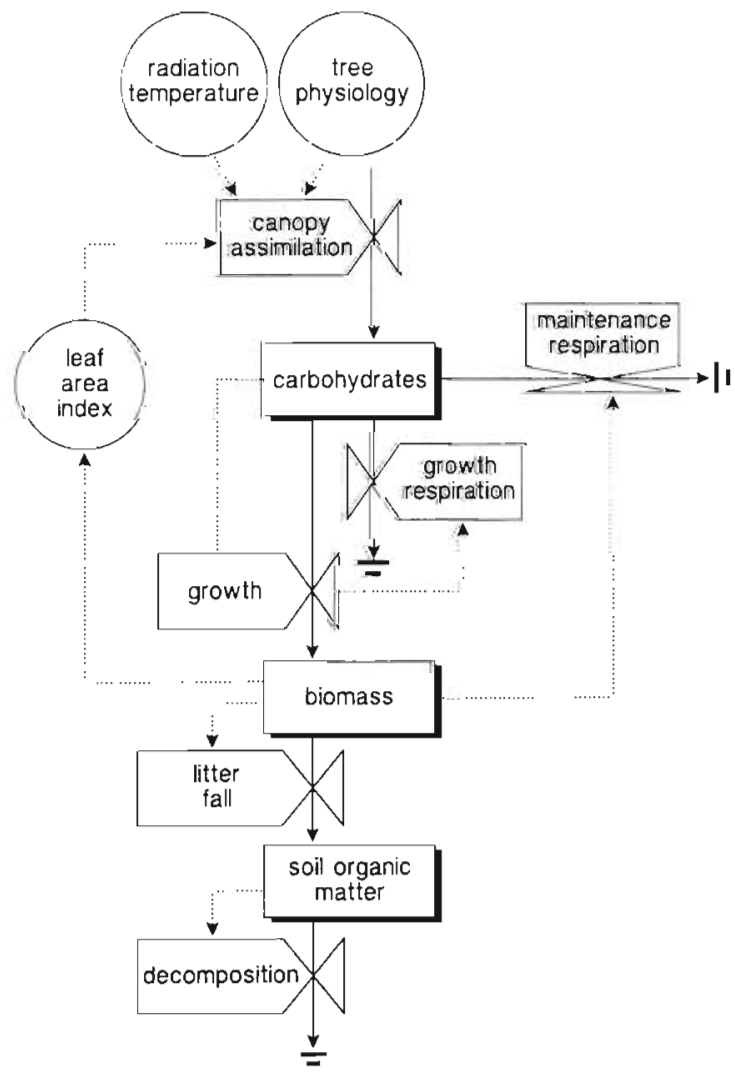

Fig. 1. Simplified diagram of the structure of FORGRO. Boxes: state variables; valves: rate variables; arrows: flows of carbon (solid lines) or information (dotted lines). (Figure redrawn from Mohren 1994)

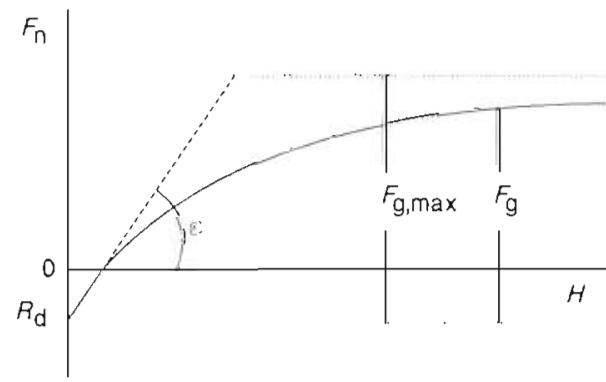

Fig. 2. Net $\mathrm{CO}_{2}$ assimilation rate in relation to light absorption by the leaf surface. See Appendix 2 for an explanation of the symbols, with their units. (Figure redrawn from Goudriaan 1992)

FORGRO: Fig. 1 presents a simplified scheme of FORGRO. For photosynthesis, the minimum was taken of the rate of photosynthesis limited by either $\mathrm{CO}_{2}$ or the maximum value measured at light saturation (Figs. 2 \& 3; Eqs. 1 to 4 in Appendix 2). Mesophyll resistance was calculated using: $r_{\mathrm{m}}=\left(C_{1}-\Gamma\right) / F_{\mathrm{m}, \mathrm{m}}$ (Fig. 2), assuming a constant ratio of internal to external $\mathrm{CO}_{2}$ concentration (Goudriaan et al, 1985). The boundary layer conductance was set at a constant value, and the stomatal conductance depends solely on temperature. The temperature dependency of the $\mathrm{CO}_{2}$ compensation point is described using a multiplier (Eq. 5). To relate the light-saturated rate of gross photosynthesis, a temperature multiplier was obtained byr linear interpolation of litcrature data, using a brôa plateau of near-unity in the range 10 to $30^{\circ} \mathrm{C}$, and declining to zero outside this temperature range. A similar approach was taken to determine the actual mesophyll resistance as a function of temperature, with values similar to the photosynthesis-temperature relationship. Daily gross canopy photosynthesis was calculated by integrating hourly over both sunlit and shaded leaf layers using a Gaussian integration scheme (Goudriaan 1986), dividing the canopy into 5 shaded and sunlit leaf layers. Growth and maintenance respiration were calculated using the approach of Penning de Vries, which is based on the costs of biosynthetic processes and the biochemical composi-

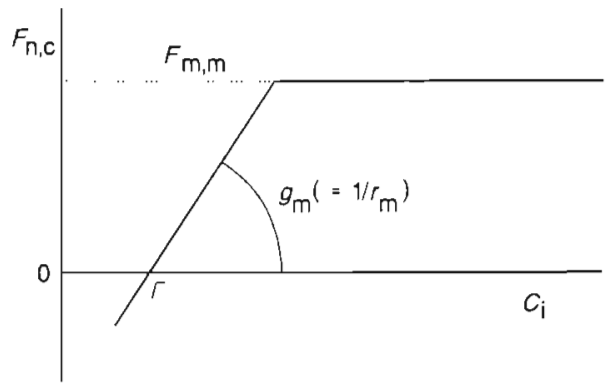

Fig. 3. Net $\mathrm{CO}_{2}$ assimilation rate in relation to internal $\mathrm{CO}_{2}$ concentration. See Appendix 2 for an explanation of the symbols, with their units. (Figure redrawn from Goudriaan 1992) 
tion of the structural biomass (Penning de Vries et al. 1989). Fixed allocation keys were used for the growth rates of the different organs, with the exception of the allocation to the foliage and the reserve pool, for which saturation curves relative to maximum values were used (Eqs. 6 \& 7). The level of reserves was modelled using a minimum equal to $5 \%$ of the biomass of each organ, and a maximum which is 4 times as high. Allocation of assimilates to the reserves has priority over all the other organs, once the full leaf stage has been reached. Daily values of the meteorological variables irradiance, minimum and maximum temperatures, humidity, wind speed and rainfall are required to run FORGRO, which uses a fixed time step of $1 \mathrm{~d}$.

PGEN: PGEN is a photosynthesis model which aims at predicting stomatal conductance and photosynthesis with a minimal use of empirical parameterization. It is based on the assumption that a leaf instantaneously optimizes its stomatal conductance as a trade-off between $\mathrm{CO}_{2}$ gain and water loss. $\mathrm{CO}_{2}$ gain affects photosynthesis according to the biochemical photosynthesis model of Farquhar \& von Caemmerer (1982).

The demand for $\mathrm{CO}_{2}$ is determined either by carboxylation limitation of Rubisco (Eq. 9), or by regeneration limitation of RuBP (Eq. 10), while the supply of $\mathrm{CO}_{2}$ depends on the difference of $\mathrm{CO}_{2}$ concentration. outside the leaf boundary layer and inside the leaf air spaces (Eq. 11). Whether the $\mathrm{CO}_{2}$ supply meets the photosynthetic demands depends on the resistance to $\mathrm{CO}_{2}$ along the pathway from outside the leaf boundary layer to the mesophyll cells (Eq. 17). Explicit functions for $r_{c, a}$ and $r_{c, i}$ are presented in PGEN, while $r_{\mathrm{c}, \mathrm{s}}$ is the resistance which is optimized numerically. Eqs. (14) to (22) provide more detail on how the variables in Eqs. (9) to (12) are calculated.

The leaf temperature is calculated from the leaf energy balance (Jones 1992). Temperature influences photosynthesis by altering the solubilities of $\mathrm{CO}_{2}$ and $\mathrm{O}_{2}$, and alters the MichaelisMenten constants of the carboxylation and oxygenation of Rubisco following the law of Arrhenius. The influence of temperature on dark respiration is modelled by a $Q_{10}$ approach.

PGEN was coupled to FORGRO by substituting it for the calculations of the gross photosynthesis $\left(F_{\mathrm{g} \text {, max }}\right)$ in the canopy module and adjusting it so that input to PGEN was: $\mathrm{CO}_{2}$ and $\mathrm{O}_{2}$ concentration in the air, relative humidity, wind speed, incidence of short wave irradiance, atmospheric pressure, air temperature and the absorbed photosynthetic active radiation at a given leaf layer. Incidence of short wave radiation was set at twice the photosynthetic active radiation available at a given leaf layer. Output of PGEN is daily gross photosynthesis.

ITE-Edinburgh model: This model presents a mechanistic approach to assimilate partitioning based on the transport of labile carbon and nitrogen, and the size and activity of meristem (Fig. 4; Eqs. 23 to 29). The transport of $\mathrm{C}$ and $\mathrm{N}$ substrate is driven by concentration differences and resistances between the organs. Counter-gradients of carbon and nitrogen substrate are formed because the foliage is the only source of $\mathrm{C}$ substrate, the roots are the only source of $N$ substrate, and the growing organs act as sinks of carbon and nitrogen. A functional root-shoot balance is attained because the acquisition of carbon depends on the level of $\mathrm{N}$ substrate of the foliage, and the acquisition of $\mathrm{N}$ depends on the level of $\mathrm{C}$ substrate in the fine roots. The growth of each organ is determined by the activity and potential size of the meristem, which depends on both the $C$ and $N$ substrate concentrations of the organ. Temperature dependency of parameters was described using a parabolic-shaped multiplier, which equals zero at $0^{\circ} \mathrm{C}$, and is maximum at $30^{\circ} \mathrm{C}$ (Eq. 30 ).

The ITE-Edinburgh model was coupled to FORGRO (ITE-FORGRO) by using the modules of FORGRO
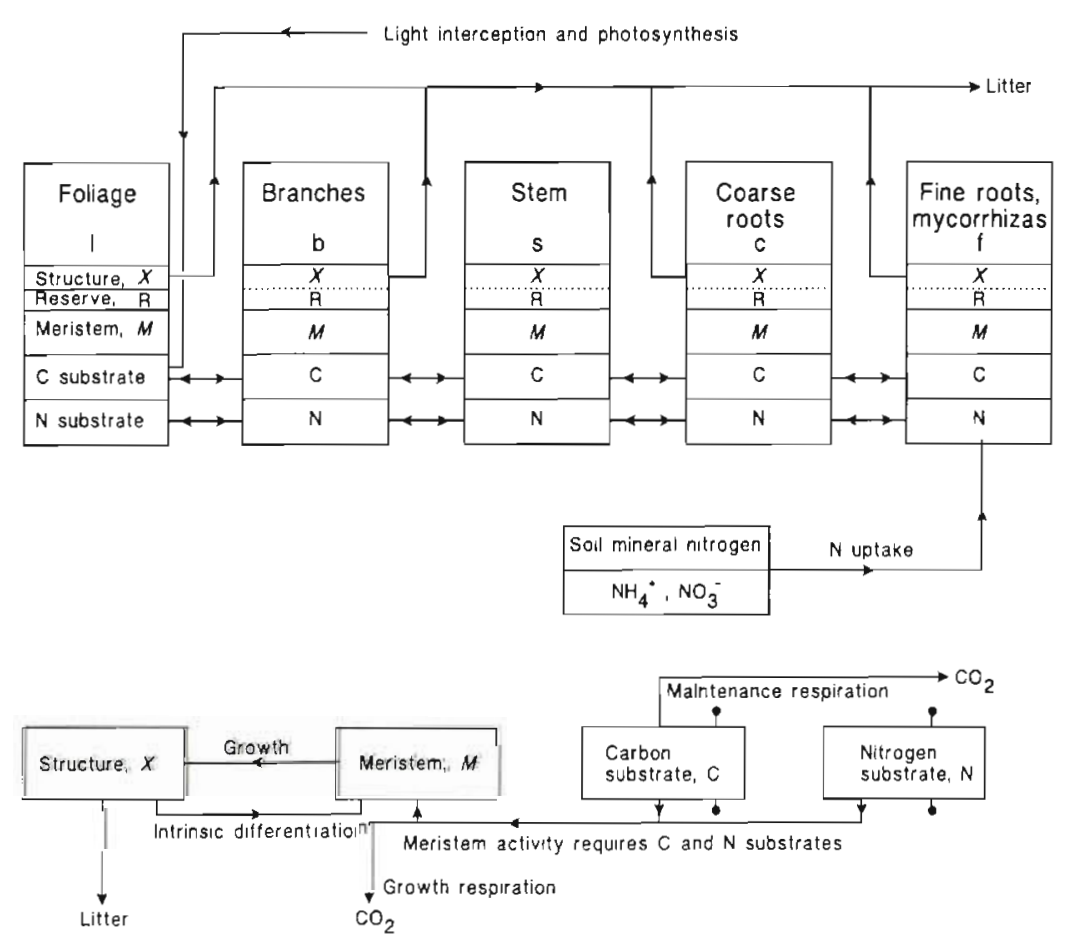

Fig. 4. Simplified diagram of the structure of ITE-FORGRO. Light interception and photosynthesis are described as in FORGRO. (Figure redrawn from Thornley 1991) 
which calculate light interception, photosynthesis and stomatal conductance. A reserve pool was required to start leaf growth after bud burst, and to allow for maintenance respiration in the leafless period. Therefore, a reserve pool was added for each organ. The growth rate of each reserve pool was set at a fixed fraction (0.05) of the growth rate of the structural biomass of the organ. Furthermore, it was assumed that the utilization of carbon and nitrogen and the respiration of the reserve pool are similar to the respiration of the structural biomass. During the build up of the canopy (the period from bud burst until full leaf), reserves are mobilized from all organs, i.e. converted into labile $\mathrm{C}$ and $\mathrm{N}$, according to a first-order process. During this phase the foliage is the only organ allowed to grow. Consequently, a gradient of both $\mathrm{C}$ and $\mathrm{N}$ substrate from the fine roots to the foliage develops, since the foliage acts as the only sink. The leaves start to photosynthesize immediately, which causes the $C$ substrate gradient to reverse as soon as the carbon production exceeds carbon utilization, or when the full leaf stage is reached. During the leafless period, the costs of maintenance respiration are directly compensated for from the reserve pool of each organ. The leaf area index was truncated to the same maximum value as used in FORGRO.

The ITE-FORGRO model was developed using SENECA v1.5, a Simulation ENvironment for ECological Application (De Hoop et al. 1992). The integration methnd was Eulerian with variable time steps. Preliminary runs indicated that it takes approximately $3 \mathrm{yr}$ for the ITE-FORGRO model to attain stable gradients of labile carbon and nitrogen. Therefore, runs were started at 1937, using average values for the phenological events, but output of the 1940 to 1953 period is presented.

\section{RESULTS}

\section{Phenology}

An impression of the importance of the differences between the phenological types can be obtained by examining the amount of light available on average during the growing period, and how this changes with a rise in temperature (Table 1). On average, most irradiance is available for Betula. Fagus and Quercus have respectively $1.4 \%$ and $3.6 \%$ less. When the temperature changes, the net result is a gain in the average available irradiance of $0.8 \%$ for Betula, $1.1 \%$ for Fagus and $0.2 \%$ for Quercus, per degree temperature rise, relative to the total cumulative irradiance available on average during the growing season for each of these phenological types. In The Netherlands, the irradiance gained on average when leaf unfolding is advanced by $1 \mathrm{~d}$ is more than twice what is lost when leaf fall advances $1 \mathrm{~d}$ (e.g. $15 \mathrm{MJ} \mathrm{m}^{-2} \mathrm{~d}^{-1}$ on 1 May and $6 \mathrm{MJ}$ $\mathrm{m}^{-2} \mathrm{~d}^{-1}$ on 15 October).

Table 2 presents the results of FORGRO, FORGROPGEN and ITE-FORGRO for the $C_{350} / T_{0}$ scenario. Clearly, the differences in phenology only cause small differences in growth and radiation use efficiency, and are consistent with the pattern between the phenological types found in Table 1. For this parameterization of the models the $P_{\mathrm{q}}$ calculated by FORGRO is similar to ITE-FORGRO, but higher than that of FORGRO-PGEN. For this parameterization of ITEFORGRO, more carbon is respired by growth respiration than by maintenance respiration, whereas in FORGRO the opposite is true. Furthermore, the growth rates of the organs differ because of the different mechanism of allocation (rcsults not presented).

The results of the 3 models when $\left[\mathrm{CO}_{2}\right]=700 \mu \mathrm{mol}$ $\mathrm{mol}^{-1}$ are that differences in the response of $P_{\mathrm{g}}$ between Betula, Fagus and Quercus increase with temperature (Figs. 5 to 7 ). The difference in the response between Fagus and Quercus increases by approximately $4 \%$ in the $C_{700} / T_{2}$ scenario and by approximately $20 \%$ in the $C_{700} / T_{7}$ scenario, for FORGRO and FORGRO-PGEN, but the corresponding increases according to ITE-FORGRO are $4 \%$ and $13 \%$, because of the different mechanism of allocation. This is consistent with the differences between the phenological types based on the change in average available irradiance with temperature (Table 1). Figs. 5 to 7 further show that the response of $P_{\mathrm{g}}$ to a doubled $\left[\mathrm{CO}_{2}\right]$ is

Table 2. Results of FORGRO, FORGRO-PGEN and ITE-FORGRO for the $C_{350} / T_{0}$ scenario for the 1940 to 1953 situation using default parameter values. RUE: radiation use efficiency: ratio of annual total dry matter production and absorbed photosynthetically active radiation ( $\mathrm{g} D \mathrm{DM} \mathrm{MJ}^{-1}$ ). See Appendix 1 for explanation of the other symbols and their units

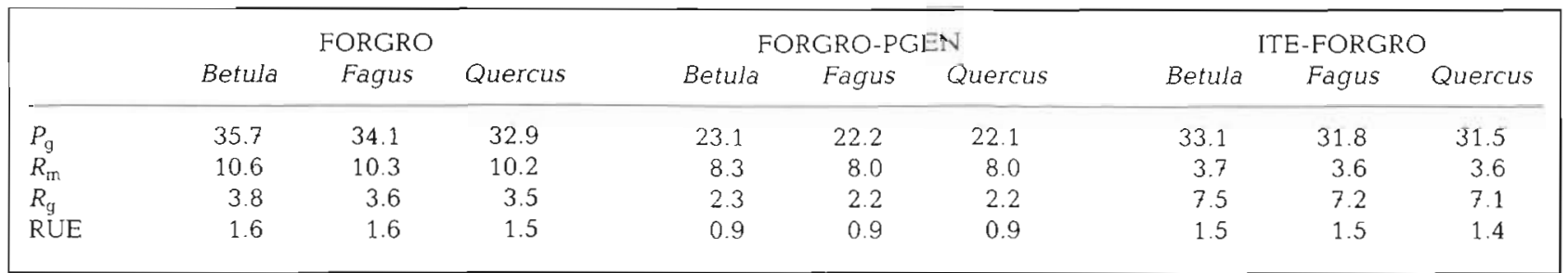




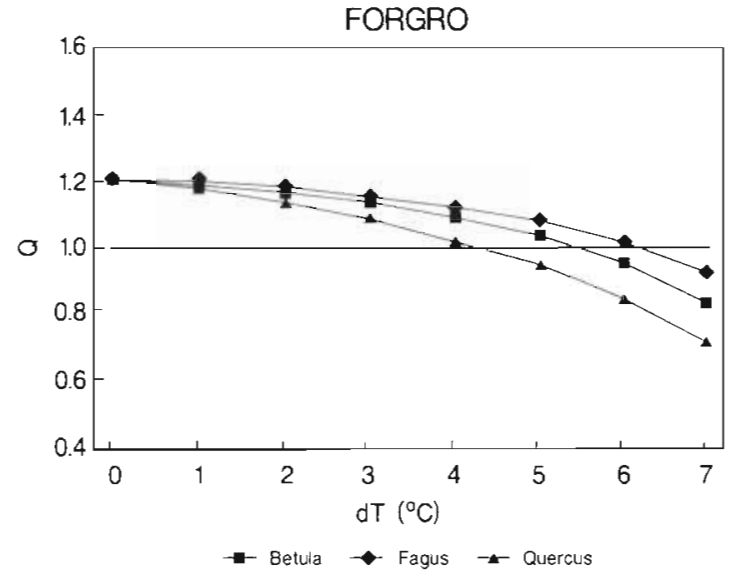

Fig. 5. Response of $P_{\mathrm{g}}$ to $2 \times\left[\mathrm{CO}_{2}\right]$ with increasing temperature, relative to the current climate (Q), according to FORGRO. Annual average over 1940 to 1953

greatest according to FORGRO-PGEN, and least in ITE-FORGRO, and that the response increases with temperature according to FORGRO-PGEN (Fig. 6), but decreases with temperature according to both FORGRO and ITE-FORGRO (Figs. 5 \& 7).

The causes of the differences between FORGRO and FORGRO-PGEN are depicted in Figs. 8 \& 9. For the current parameterization of FORGRO and FORGROPGEN it can be seen that: (1) FORGRO yields a higher $P_{\mathrm{g}}$ than FORGRO-PGEN for any $\mathrm{CO}_{2}$, temperature and light combination; (2) the sensitivity of $P_{\mathrm{g}}$ to $\mathrm{CO}_{2}$ at a constant light level increases with temperature according to FORGRO-PGEN, but decreases slightly according to FORGRO; (3) the sensitivity of $P_{\mathrm{g}}$ to $\mathrm{CO}_{2}$ at $10^{\circ} \mathrm{C}$ increases with irradiance similarly in FORGRO and FORGRO-PGEN $N_{i}$ and (4) there is a temperature and light interaction for the sensitivity of $P_{\mathrm{g}}$ to $\mathrm{CO}_{2}$ accord-

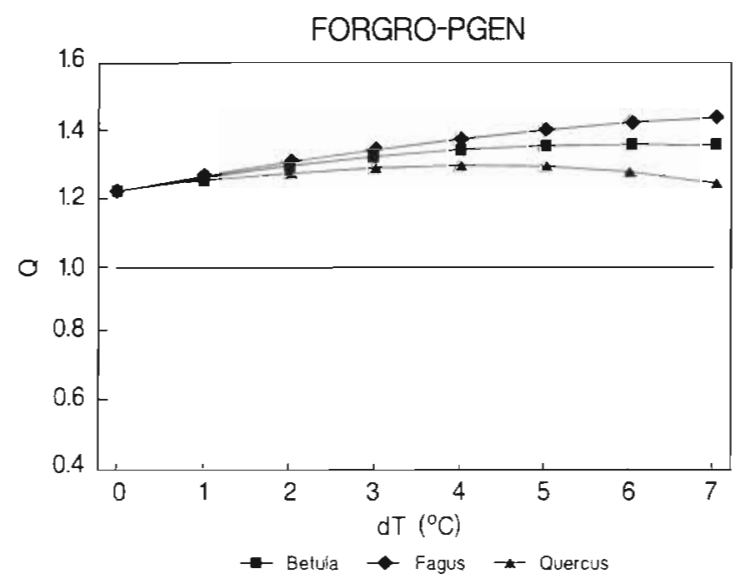

Fig. 6. Response of $P_{\mathrm{g}}$ to $2 \times\left[\mathrm{CO}_{2}\right]$ with increasing temperature, relative to the current climate (Q), according to FORGROPGEN. Annual average over 1940 to 1953

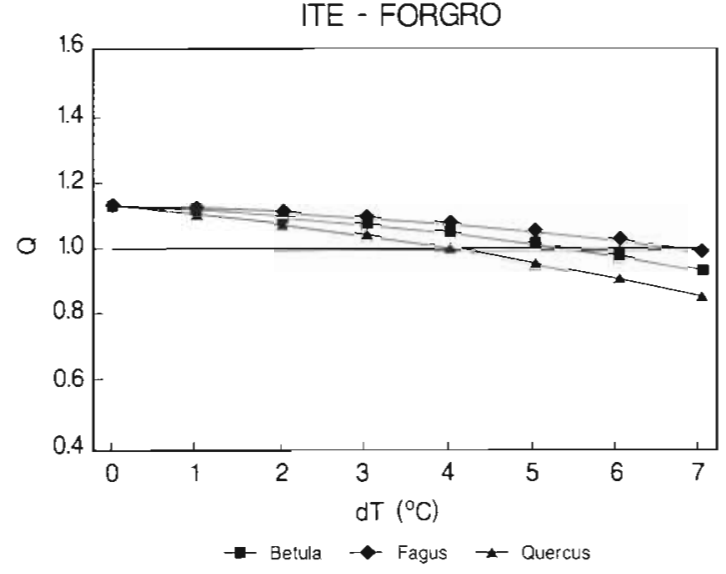

Fig. 7. Response of $P_{\mathrm{g}}$ to $2 \times\left[\mathrm{CO}_{2}\right]$ with increasing temperature, relative to the current climate $(Q)$, according to ITE-FORGRO. Annual average over 1940 to 1953

ing to FORGRO-PGEN, but not according to FORGRO. The consequence of these differences between FORGRO and FORGRO-PGEN are that in FORGRO and thus ITE-FORGRO, the increase in respiration with temperature is not compensated for by an increase in photosynthesis (Figs. $5 \& 7$ ), whereas this is the case in FORGRO-PGEN (Fig. 6).

\section{Sensitivity analysis}

A sensitivity analysis was performed to evaluate which parameters are most important in determining the response of gross photosynthesis, $P_{\mathrm{g}}$, to an increase

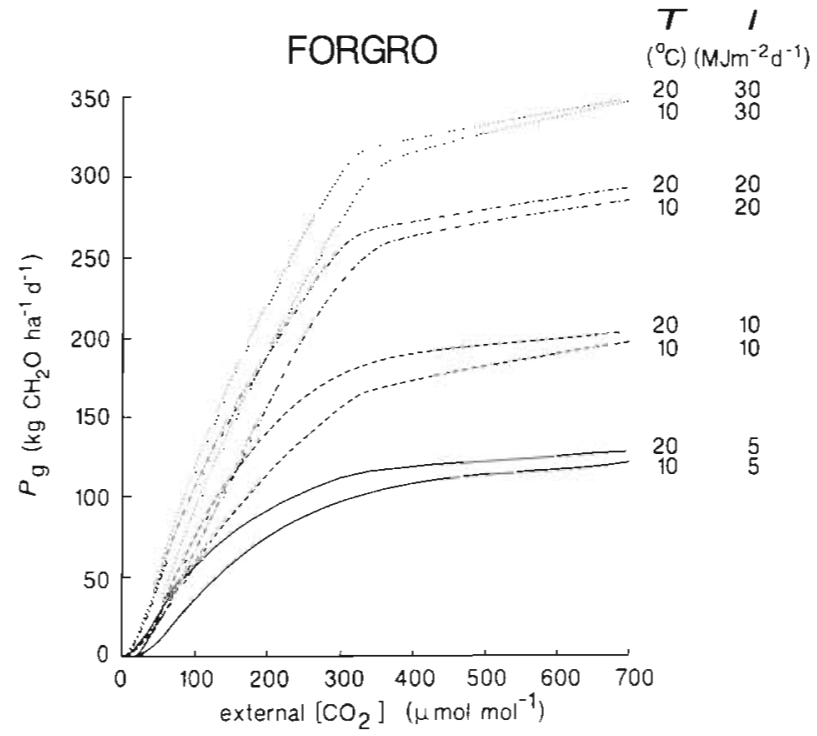

Fig. 8. Response of $P_{\mathrm{g}}$ to $\mathrm{CO}_{2}$ at different temperature and light levels, according to FORGRO 


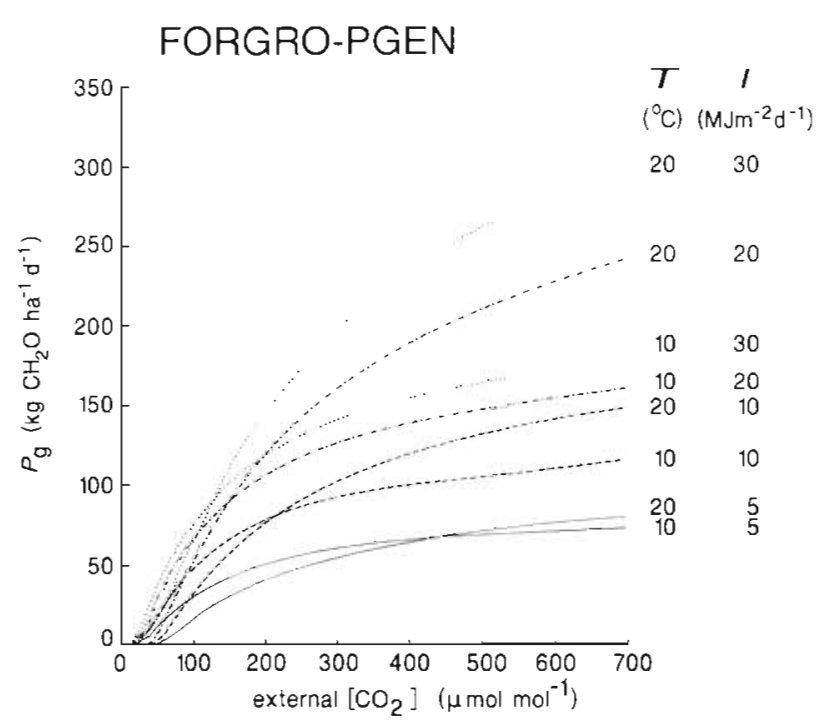

Fig. 9. Response of $P_{\mathrm{g}}$ to $\mathrm{CO}_{2}$ at different temperature and light levels, according to FORGRO-PGEN

of both $\mathrm{CO}_{2}$ and temperature. The response of $P_{\mathrm{g}}$ to the $C_{700} / T_{2}$ scenario relative to the $C_{350} / T_{0}$ scenario was used to compare the sensitivities of the parameters. The general trend which can be seen for FORGRO is that when a parameter is set so that $P_{\mathrm{g}}$ is lower than the default parameter value, then the response to the $C_{700} / T_{2}$ scenario is greater (Fig 10) For example, a high ratio between internal and external $\mathrm{CO}_{2}$ concentration, $C_{\mathrm{i}} / C_{\mathrm{a}}$, reduces the $P_{\mathrm{g}}$ relative to a low ratio; consequently $P_{\mathrm{g}}$ is increased more by the $C_{700} / T_{2}$

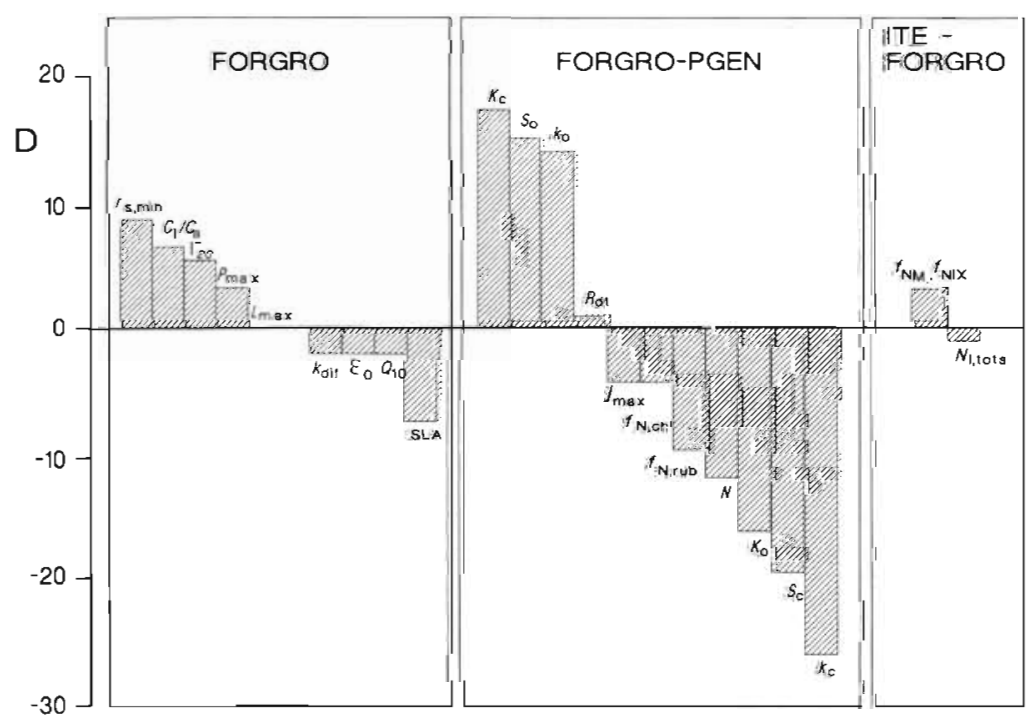

Fig. 10. Difference (D) between the responses of $P_{\mathrm{g}}$ to the $C_{700} / T_{2}$ scenario relative to the benchmark scenario at high $(+25 \%)$ and low $(-25 \%)$ value of the parameter indicated scenario compared with the low ratio (24\% versus $18 \%$ ). High values of $C_{1} / C_{\mathrm{d}}$, the $\mathrm{CO}_{2}$ compensation point, and stomatal resistance, and low values of the initial light use efficiency, the light extinction coefficient and specific leaf area reduce $P_{g}$, and thus show the large response to $C_{700} / T_{2}$. However, for $P_{\max }$ the opposite is true: the largest response to $C_{700} / T_{2}$ is at the high value of $P_{\max }$ which clearly gives high values of $P_{\mathrm{g}}$. This was caused by the fact that at low $P_{\max }$, this asymptote was met more frequently than at high $P_{\max }$ thus the sensitivity to the scenarios is less. In general it can be concluded that response of $P_{g}$ in FORGRO to the $C_{700} / T_{2}$ scenario is similar over a wide range of values of the main parameters which determine light interception and photosynthesis.

A clear effect of the PGEN formulation is that the response of $P_{\mathrm{g}}$ to the scenarios increases or decreases, depending on the value assigned to a parameter. This is especially true for the parameters describing the temperature response of a parameter $\left(\Delta S, m, n, E_{a}, E_{\mathrm{d}}\right)$. The reason for this can be seen from Eqs. (20) to (22): a change of 1 unit in a parameter in the exponent is equivalent to leaf temperature changing by approximately $0.03^{\circ} \mathrm{C}$, because the temperature is presented in Kelvin. Thus, these parameters need to be estimated accurately, although a change of $25 \%$ in the values of these parameters may exceed the range which is found experimentally.

For the ITE-FORGRO model, the most proñuinced effect was found for the total leaf nitrogen ( $\left.N_{\text {l.tots }}\right)$ and the fraction nitrogen in meristem and structural biomass of all organs $\left(f_{\mathrm{N} M \mathrm{M}}\right.$ and $\left.f_{\mathrm{Ni}}\right)$. However, the magnitude of the response of $P_{g}$ to the scenario is only slightly affected by a large change in the values of these parameters. The absolute response of the other parameters of the ITE-FORGRO model tested in this manner was much less than that of the nitrogen parameters, whilst only the coefficient determining the potential meristem size showed a $P_{\mathrm{g}}$ response which differed more than $2 \%$ between the scenarios.

\section{DISCUSSION AND CONCLUSIONS}

Both FORGRO and FORGRO-PGEN showed that the difference in the response of gross photosynthesis to a doubled $\mathrm{CO}_{2}$ concentration between the phenological types ranges from 4 to $20 \%$ if the corresponding temperature rises by 2 to $7^{\circ} \mathrm{C}$, respectively. However, these models diverge in the degree of the 
response of $P_{\mathrm{g}}$ to doubled $\mathrm{CO}_{2}$ scenarios: in FORGRO this response ranges on average from $+20 \%$ when there is no temperature rise to $-16 \%$ when the rise is $7^{\circ} \mathrm{C}$, while the corresponding range according to FORGRO-PGEN is $+22 \%$ to $+36 \%$. These differences can be attributed to differences in the response of $P_{\mathrm{g}}$ to $\left[\mathrm{CO}_{2}\right]$. In FORGRO-PGEN this response enhances when temperature and irradiance increase, whilst in FORGRO this interaction is weaker (Figs. 8 \& 9). Consequently, in FORGRO-PGEN the increase in photosynthesis exceeds the increase in respiration, whereas in FORGRO and ITE-FORGRO the break-even point lies at or above a temperature increase of $5^{\circ} \mathrm{C}$. The $\mathrm{CO}_{2} \times$ temperature interaction is frequently reported in the literature, and is stressed as an important aspect for the study of climate change effects (e.g. Idso \& Idso 1994, Kirschbaum 1994). However, the absence of a response or a decline of the relative stimulation of biomass of perennial plants at high $\mathrm{CO}_{2}$ as temperature increases has also been reported (Ziska \& Bunce 1994, and literature therein).

According to the transport-resistance mechanism of allocation (Thornley 1991) the response of $P_{\mathrm{g}}$ to the scenarios with doubled $\mathrm{CO}_{2}$ is less compared with FORGRO and FORGRO-PGEN: relative to the $C_{350} / T_{0}$ scenario it is $+13 \%$ for no temperature rise and $-6 \%$ for a rise of $7^{\circ} \mathrm{C}$. Callaway et al. (1994) presented experimental evidence for a reduced response of growth to enhanced $\mathrm{CO}_{2}$ because of an altered allocation pattern. They found that the initial stimulating effect of $\mathrm{CO}_{2}$ on the growth of Pinus ponderosa seedlings, and its enhancement by increased temperature, disappeared after 2 mo because of an increased allocation of biomass to the roots and other non-photosynthesizing tissues. Furthermore, the differences in the response of $P_{\mathrm{g}}$ to a $2 \times\left[\mathrm{CO}_{2}\right]$ scenario between the phenological types are less than FORGRO and FORGRO-PGEN: $4 \%$ if the corresponding temperature rises by $2^{\circ} \mathrm{C}$ and $13 \%$ if it rises by $7^{\circ} \mathrm{C}$ (Fig. 6). These features of the transport-resistance model make it worthwhile validating this model for a number of tree species.

Figs. 5 to 7 can be used to evaluate the temperature increase predicted by general circulation models (GCMs). Four well-known GCMs are OSU, GISS, GFDL and UKMO, which predict that mean annual temperature will increase by $3.0,4.0,5.3$ and $6.5^{\circ} \mathrm{C}$, respectively (Leemans 1992). However, these models use $\mathrm{CO}_{2}$ equivalents to calculate the increase in radiative forcing due to an increase in greenhouse gasses. Approximately half of these greenhouse gasses is carbon dioxide, the other half consists of methame, CFCs etc. (Houghton et al. 1990). Furthermore, according to the GCM scenarios the temperature increases more during winter than during summer, rather than uniformly over the year (Leemans 1992). Conse- quently, the GCM scenarios affect the timing of leaf unfolding more than the timing of leaf fall, and respiration during the growing season is less for the GCM scenarios than for the uniform temperature scenarios. Thus, the equivalent uniform temperature scenario involves a somewhat higher increase in temperature than the annual mean temperature increase of the GCM scenario

The sensitivity analysis of the parameters of the models affecting photosynthesis showed that for FORGRO and FORGRO-ITE there is generally little interaction between the value of a parameter and the degree of the response of growth to the $C_{700} / T_{2}$ climate change scenario, although many parameters strongly affect the response in absolute terms (Fig. 10). Typically, this sensitivity over a broad range of parameter values is similar in magnitude to the difference between the phenological types in the $C_{700} / T_{2}$ scenario (Figs. $5 \&$ 7). For FORGRO-P(IEN, however, the degree of the response of $P_{\mathrm{g}}$ to the $C_{700} / T_{2}$ scenario depends on the value of a parameter (Fig, 10). This was especially the case for the parameters describing the Michaelis-Menten kinetics of Rubisco, and the effect of temperature on these parameters. Also the effect of nitrogen is such that at low values of the nitrogen parameters the response of $P_{\mathrm{q}}$ to the $C_{700} / T_{2}$ scenario is greater than at high values of these parameters (Fig. 10). For these parameters, this sensitivity is greater than the difference between the phenological types in the $C_{700} / T_{2}$ scenario (Fig. 6). The sensitivity of the response to a variation in the parameter values in FORGRO-PGEN indicates that these parameters must be determined accurately in order to evaluate the effects of $\mathrm{CO}_{2}$ and temperature on growth. Currently, they are available for only a few species. Furthermore, some of the parameters of the PGEN formulation vary considerably both between and within species (Wullschleger 1993).

An analysis of uncertainty propagation in FORGRO showed that variation in $P_{\max }, Q_{10}, \varepsilon_{0}$ and SLA within $95 \%$ of their uncertainty limits yielded uncertainties of $19,9,9$ and $2 \%$, respectively, of the relative standard deviation of the annual growth rate (Van der Voet \& Mohren 1994). In a sensitivity analysis of PGEN it was found that the sensitivity indices (ratio of the relative change in a parameter to the relative change in net photosynthesis) of $k_{\mathrm{c}}, K_{\mathrm{c}}, N, K_{\mathrm{o}}, f_{\mathrm{n}, \mathrm{rub}}, k_{0}, f_{\mathrm{N}, \mathrm{chl}}$ and $j_{\max }$ were $0.7,0.6,0.6,0.4,0.4,0.3,0.2$ and 0.2 , respectively (Friend 1995). Thus, the uncertainty or sensitivity of these output variables to a small variation in a parameter is not directly applicable for inferring the importance of this parameter on the effects of a climate change scenario on the output variable.

In this study, only the direct effect of temperature on phenology was taken into account. However, nutrients 
and $\mathrm{CO}_{2}$ are known to interact with temperature. Murray et al. (1994) showed that for some Picea sitchensis clones, an increased $\mathrm{CO}_{2}$ yields a delayed bud burst and an advanced bud set under low nutrient supply. This could shorten the growing season by $3 \mathrm{wk}$. Under high nutrient supply this effect was much less. Increasing temperature counteracted the $\mathrm{CO}_{2}$ effect, resulting in an advanced bud burst, which was less compared to the situation where only temperature was increased. Such complex interacting effects, which are clone specific, greatly complicate the evaluation of the effects of climate change on the growth of trees.

Acknowledgements. I thank Prof J. Goudriaan, Dr G. M. J. Mohren and the Ph.D. group of the C. T de Wit Graduate School of Production Ecology for valuable comments on earlier drafts of the manuscript.

Appendix 1. Symbols of variables and parameters with their dimensions. The value indicates the default value for the parameter

\begin{tabular}{|c|c|c|c|}
\hline Symbol & Definition & Units & Value \\
\hline \multicolumn{4}{|c|}{ Variables } \\
\hline$P_{9}$ & Gross photosynthesis & $\mathrm{t} \mathrm{CH}{ }_{2} \mathrm{O} \mathrm{ha} \mathrm{y}^{-1} \mathrm{yr}^{-1}$ & \\
\hline$R_{\mathrm{m}}$ & Maintenance respiration & $\mathrm{t} \mathrm{CH}_{2} \mathrm{O} \mathrm{ha}^{-1} \mathrm{yr}^{-1}$ & \\
\hline$R_{\mathrm{g}}$ & Growth respiration & $\mathrm{t} \mathrm{CH}_{2} \mathrm{O} \mathrm{ha}^{-1} \mathrm{yr}^{-1}$ & \\
\hline$G_{i}$ & Growth: $i=l$, leaves; $i=b$, branches $;=s$, stem $; i=c$, coarse roots $; i=f$, fine roots & t DM ha-1 $\mathrm{yr}^{-1}$ & \\
\hline \multicolumn{4}{|c|}{ Parameters } \\
\hline SLA & Specific leaf area & $\mathrm{m}^{2} \mathrm{~kg}^{-1}$ & 20 \\
\hline$L_{\max }$ & Maximum leaf area index & $\mathrm{m}^{2}$ (leaf) $\mathrm{m}^{-2}$ (ground) & 6 \\
\hline$P_{n, \max }$ & Maximum rate of net photosynthesis & $\mathrm{mg} \mathrm{CO}_{2} \mathrm{~m}^{2} \mathrm{~s}^{-1}$ & 0.56 \\
\hline$\Gamma_{20}$ & $\mathrm{CO}_{2}$ compensation point at $20^{\circ} \mathrm{C}$ & $\mu \mathrm{mol} \mathrm{mol}-1$ & 50 \\
\hline$\varepsilon_{0}$ & Initial light use efficiency & $\mathrm{kg} \mathrm{CO} \mathrm{J}^{-1}$ & 0.45 \\
\hline$C_{\mathrm{i}} / C_{\mathrm{a}}$ & Ratio internal to external $\mathrm{CO}_{2}$ concentration & & 0.7 \\
\hline$k_{\mathrm{dif}}$ & Light extinction coefficient of canopy & & 0.65 \\
\hline$R_{\mathrm{d} 20}$ & Dark respiration at $20^{\circ} \mathrm{C}$ & $\mathrm{mg} \mathrm{CO} 2 \mathrm{~m}^{-2} \mathrm{~s}^{-1}$ & 0.028 \\
\hline$Q_{10}$ & Increase of $R_{d}$ given $10^{\circ} \mathrm{C}$ temperature increase & & 2.0 \\
\hline
\end{tabular}

Appencuix 2. Equations

\section{FORGRO}

Leaf photosynthesis

$$
\begin{aligned}
& F_{\mathrm{n}}=F_{\mathrm{g}, \max }\left(1-e^{\frac{-\varepsilon H_{\max }}{F_{\mathrm{g} \max }}}\right)-R_{\mathrm{d}} \\
& F_{\mathrm{g}, \max }=\operatorname{MIN}\left(F_{\mathrm{n}, \mathrm{c}}, F_{\mathrm{n}, \max }\right)+R_{\mathrm{d}} \\
& F_{\mathrm{n}, \mathrm{c}}=\frac{C_{\mathrm{a}}-\Gamma}{r_{\mathrm{m}}+1.6 r_{\mathrm{s}}+1.4 r_{\mathrm{b}}} \\
& \varepsilon=\varepsilon_{0} \frac{C_{\mathrm{d}}-\Gamma}{C_{\mathrm{a}}+2 \Gamma} \\
& \Gamma=\Gamma_{20} e^{0.07(T-20)}
\end{aligned}
$$

$a_{r e}, a_{1}, a_{b}$, Allocation of assimilates to the

$a_{\mathrm{st}} \quad$ reserve pool, leaves, branches and stem

$\mathrm{C}_{\mathrm{a}} \quad$ Ambient $\mathrm{CO}_{2}$ concentration

$F_{\text {g,max }} \quad$ Max gross photosynthesis

$F_{\mathrm{n}} \quad$ Net rate of photosynthesis

$F_{\mathrm{n}, \mathrm{c}}$

$F_{\mathrm{n}, \mathrm{madx}}$

$\mathrm{CO}_{2}$ limited net photosynthesis

$F_{\mathrm{m}, \mathrm{m}}$

Maximum net photosynthesis at

high $\mathrm{CO}_{2}$ and light levels

Maximum endogenous photo-

synthetic capacity at high $\mathrm{CO}_{2}$

and light levels

$H_{\mathrm{abs}}$

Absorbed PAR

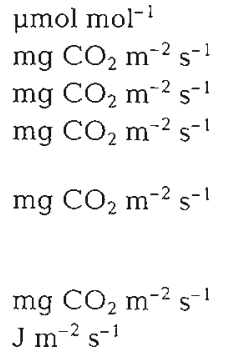

Allocation

$$
\begin{aligned}
& a_{\mathrm{re}}=\frac{R-R_{\max }}{R_{\max }} \\
& a_{1}=\frac{L-L_{\max }}{L_{\max }} \\
& a_{\mathrm{s} 1}=1-\left(a_{1}+a_{b}\right)
\end{aligned}
$$

$R, R_{\max }$ Reserve pool, and maximum

level of reserve pool $\quad \mathrm{kg} \mathrm{CH}_{2} \mathrm{O} \mathrm{ha}^{-1}$

$R_{\mathrm{d}} \quad$ Dark respiration rate $\quad \mathrm{mg} \mathrm{CO} \mathrm{CO}^{-2} \mathrm{~s}^{-1}$

$I_{\mathrm{m}}, r_{\mathrm{s}}, r_{\mathrm{b}}$ Mesophyll, stomatal and boundary layer resistance $\mathrm{s} \mathrm{m}^{-1}$

$T$ Temperature $\quad{ }^{\circ} \mathrm{C}$

$L, L_{\max }$ Leaf area index, and maximum leaf area index $m^{2}$ (leaf) $m^{-2}$ (ground)

$\Gamma, \Gamma_{20} \quad \mathrm{CO}_{2}$ compensation point, and $\mathrm{CO}_{2}$ compensation point at $20^{\circ} \mathrm{C}$

$\mu \mathrm{mol} \mathrm{mol}{ }^{-1}$ Initial light use efficiency $\mu \mathrm{g} \mathrm{CO}_{2} \mathrm{~J}^{-1}$ 
Appendix 2 (continued)

\section{PGEN}

Leaf photosynthesis

$$
\begin{aligned}
& A_{n, c}=\frac{V_{c \max }\left(C_{1}-\Gamma_{.}\right)}{C_{1}+K_{c}\left(1+\frac{Q_{1}}{K_{0}}\right)}-R_{\mathrm{d}} \\
& A_{n, J}=\frac{J\left(C_{1}-\Gamma_{.}\right)}{4.5 C_{i}+10.5 \Gamma_{.}}-R_{\mathrm{d}} \\
& A_{n, s}=\frac{C_{\mathrm{a}}-C_{\mathrm{i}}}{r_{\mathrm{c}}}-\frac{C_{\mathrm{a}}-C_{\mathrm{i}}}{2} \frac{E R T}{P} \\
& \Gamma .=\frac{0.5 V_{\mathrm{o}, \max } K_{\mathrm{c}} O_{\mathrm{i}}}{V_{\mathrm{c} \max } K_{\mathrm{o}}} \\
& J=\frac{J_{\max } H_{\mathrm{abs}}}{2.1 J_{\mathrm{mdx}}+H_{\mathrm{dbs}}} \\
& V_{1 \max }=k_{1} E_{1}, \mathrm{i}: \mathrm{c}, \mathrm{o} \\
& J_{\max }=\frac{j_{\max } f_{\mathrm{N}, \text { chl }} N}{0.056} \\
& E_{\mathrm{t}}=0.0909 f_{\mathrm{N} \text {,rub }} \mathrm{N} \\
& r_{\mathrm{C}}=r_{\mathrm{C}, \mathrm{a}}+r_{\mathrm{C}, \mathrm{S}}+r_{\mathrm{C}, \mathrm{i}} \\
& R_{\mathrm{d}}=R_{\mathrm{dT}} N \\
& K_{1}=\frac{K_{\text {i.chl }} D}{S_{1}}, \mathrm{i}: \mathrm{c}, \mathrm{o}
\end{aligned}
$$

\section{$A_{n, c,} A_{n, r 1}$ Carboxylation-limited, RuBP}

$A_{n, s} \quad$ regeneration-limited, and stomatal resistance-limited rate of net photosynthesis

$C_{1}, C_{0} \quad\left[\mathrm{CO}_{2}\right]$ in leaf air spaces, and in air outside the leaf boundary layer $\mathrm{mol} \mathrm{m}^{-3}$

D Concentration of air in leaf internal air spaces

E Transpiration

$E_{a} \quad$ Activation energy

$E_{\mathrm{d}} \quad$ Deactivation energy

$E_{t} \quad$ Leaf Rubisco catalytic site content in leaf

$f_{\mathrm{N}, \text { rub }}, f_{\mathrm{N}, \mathrm{chl}}$ Fraction nitrogen in Rubisco, and chlorophyll

$H_{\mathrm{dbs}} \quad$ Absorbed PAR

$J$

$j_{\text {max }}$

Potential electron transport rate

PAR-saturated potential

electron transport rate

(temperature dependent)

$J_{\text {mad }} \quad$ PAR-saturated electron

transport rate

$k_{c} k_{0} \quad$ Rubisco carboxylation, and oxygenation turnover number $\mathrm{mol}$ (mol sites) ${ }^{-1} \mathrm{~s}^{-1}$

$K_{\mathrm{c}}, K_{\mathrm{o}}$

$M-M$ constant for carboxylation, and oxygenation of Rubisco (air space equivalents)

$\mathrm{mol} \mathrm{m}^{-3}$

$K_{c, c h i}, K_{o, c h i} M-M$ constant for carboxylation, and oxygenation of Rubisco (temperature dependent) $\mathrm{mol} \mathrm{CO} \mathrm{C}^{-2} \mathrm{~s}^{-1}$

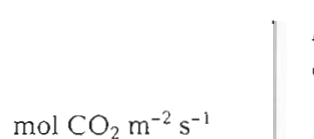

$\begin{array}{ll}N & \text { Leaf nitrogen content } \\ \mathrm{O}_{1} & \mathrm{O}_{2} \text { concentration in leaf } \\ & \text { air spaces }\end{array}$

$P, P_{0} \quad$ Atmospheric pressure, and

standard atmospheric pressure

$R \quad$ Gas constant

$r_{c} \quad$ Resistance to $\mathrm{CO}_{2}$ from air

$\mathrm{mol} \mathrm{m} \mathrm{m}^{-3}$

mol $\mathrm{H}_{2} \mathrm{O} \mathrm{m}^{-2} \mathrm{~s}^{-1}$

$\mathrm{J} \mathrm{mol}^{-1}$

$\mathrm{J} \mathrm{mol}^{-1}$

$\mathrm{mol} \mathrm{m} \mathrm{m}^{-2}$

mol quanta $\mathrm{m}^{-2} \mathrm{~s}^{-1}$

$\mathrm{mol} \mathrm{e}^{-} \mathrm{m}^{-2} \mathrm{~s}^{-1}$

\section{Temperature functions}

$$
\begin{aligned}
& x=a e^{\frac{E_{a}}{R T_{1}}}, x: k_{\mathrm{c}}, k_{0}, k_{\mathrm{c}, \mathrm{chl}}, R_{\mathrm{dt}} \\
& j_{\max }=\frac{e^{\frac{-E_{\mathrm{a}}}{R T}}}{1+e^{\frac{\Delta S T_{1}-E_{\mathrm{d}}}{R T}}}
\end{aligned}
$$

$$
S_{1}=\frac{m}{e^{\frac{-g}{R T_{1}}}} \frac{P}{P_{0}}, \mathrm{i}: \mathrm{C}_{1} \mathrm{O}
$$

outside the leaf boundary layer

to the mesophyll surface

$r_{c, d} \quad$ Resistance to $\mathrm{CO}_{2}$ transfer across leaf boundary layer

Resistance to $\mathrm{CO}_{2}$ from Inside leaf surface to mesophyll surface

$5 \mathrm{~m}^{-1}$

$r_{C, S} \quad$ Resistance to $\mathrm{CO}_{2}$ across leaf surface

$R_{\mathrm{d}} \quad$ Mitochondrial respiration

$R_{d T} \quad$ Mitochondrial respiration (temperature dependent)

$S_{c}, S_{0} \quad$ Solubility of $\mathrm{CO}_{2}$, and $\mathrm{O}_{2}$ in $\mathrm{mol} \mathrm{e} \mathrm{mol} \mathrm{chl}^{-1} \mathrm{~s}^{-1}$ $\mathrm{mol} \mathrm{e} \mathrm{e}^{-2} \mathrm{~s}^{-1}$

$T_{,} T_{1}$ water

$\mathrm{kg} \mathrm{m} \mathrm{m}^{-2}$

$\mathrm{mol} \mathrm{O} \mathrm{m}^{-3}$

$\mathrm{Pa}$

$\mathrm{J} \mathrm{K}^{-1} \mathrm{~mol}^{-1}$

$5 \mathrm{~m}^{-1}$

$s m^{-1}$

$s \mathrm{~m}^{-1}$

$\mathrm{mol} \mathrm{CO} \mathrm{m}^{-2} \mathrm{~s}^{-1}$

$\mathrm{mol} \mathrm{CO} \mathrm{kg} \mathrm{N}^{-1} \mathrm{~s}^{-1}$

$\mathrm{mol} \mathrm{m}^{-3}$

Average of leaf and air temperature, and leaf temperature $K$

$V_{c, \max }, V_{0, \max }$ Maximum rate of carboxylation, and oxygenation of Rubisco

$\mathrm{mol} \mathrm{CO} 2 \mathrm{~m}^{-2} \mathrm{~s}^{-1}$

Г. Photosynthesis compensation

$\left[\mathrm{CO}_{2}\right]$ in leaf air spaces in absence

of mitochondrial respiration $\mathrm{mol} \mathrm{CO} \mathrm{Cm}^{-3}$

$\Delta S \quad$ Entropy parameter

$a, m, n$

Empirical constants 
Appendix 2 (contınued)

\section{ITE-Edinburgh}

Differential equations

$$
\begin{aligned}
& \frac{\mathrm{d} M_{1 \mathrm{M}}}{\mathrm{d} t}=G_{\mathrm{MiM}}-L_{\mathrm{MiMdit}} \\
& \frac{\mathrm{d} M_{\mathrm{IR}}}{\mathrm{d} t}=G_{\mathrm{MiR}}-L_{\mathrm{M} \text { IRLK }}-M_{\mathrm{M}, \mathrm{R}} \\
& \frac{\mathrm{d} M_{i \mathrm{X}}}{\mathrm{d} t}=G_{\mathrm{MiX}}-L_{\mathrm{MiX}}-L_{\mathrm{M} M \mathrm{Mdr}} \\
& \frac{\mathrm{d} M_{\mathrm{IC}}}{\mathrm{d} t}=T_{\mathrm{C}(1+1)+}-T_{\mathrm{CIL(1-1)}}-R_{1 \times \mathrm{Xm}}-U_{\mathrm{CIG}}+M_{\mathrm{CIR}}
\end{aligned}
$$

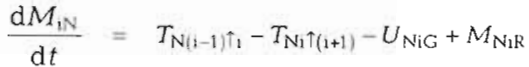

Leaves (1):

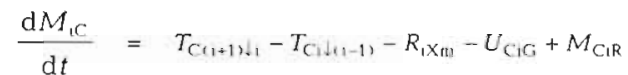

\begin{tabular}{|c|c|}
\hline$G_{\mathrm{ML}}$ & Growth rate of meristem \\
\hline$G_{\mathrm{MIR}}$ & Growth rate of reserves \\
\hline$G_{M i X}$ & Growth rate of structure \\
\hline$\stackrel{r}{L}_{\text {MiMdir }}$ & $\begin{array}{l}\text { Luss in meristems to } \\
\text { intrinsic differentiation }\end{array}$ \\
\hline$L_{\text {MiRlit }}$ & Loss in reserves to litter \\
\hline$L_{\text {MiXlit }}$ & Loss in structure to litter \\
\hline$M_{\mathrm{CIR}}$ & Mobilization of carbon from reserves \\
\hline$M_{\mathrm{NiR}}$ & Mobilization of nitrogen from reserves \\
\hline$P_{C}$ & Canopy gross photosynthesis rate \\
\hline
\end{tabular}

Fine roots (f):

$$
\frac{\mathrm{d} M_{\mathrm{TN}}}{\mathrm{d} t}=U_{\mathrm{N}}-T_{\mathrm{N} T \mathrm{TC}}-U_{N G \mathrm{C}}+M_{\mathrm{NIR}}
$$

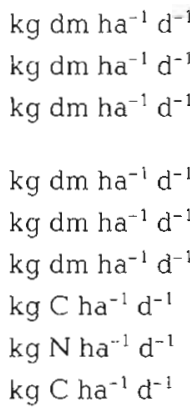

Temperature function

$$
f(T)=\frac{\left(T-T_{0}\right)\left(2 T_{\max }-T_{0}-T\right)}{\left(T_{\text {ref }}-T_{0}\right)\left(2 T_{\max }-T_{0}-T_{\text {rel }}\right)}
$$

(1)


Idso KE, Idso SB (1994) Plant responses to atmospheric $\mathrm{CO}_{2}$ enrichment in the face of environmental constraints: a review of the past 10 years' research. Agr Forest Meteorol 69: 153-203

Jones HG (1992) Plants and microclimate. A quantitative approach to environmental plant physiology. Cambridge University Press, Cambridge, p 428

Kirschbaum MUF (1994) The sensitivity of $\mathrm{C}_{3}$ photosynthesis to increasing $\mathrm{CO}_{2}$ concentration: a theoretical analysis of its dependence on temperature and background $\mathrm{CO}_{2}$ concentration. Plant Cell Environ 17:747-754

Kramer K (1994) A modelling analysis on the effects of climatic warming on the probability of spring frost damage to tree species in The Netherlands and Germany. Plant Cell Environ 17:367-377

Kramer K (1995) Phenotypic plasticity of the phenology of seven European tree species, in relation to climatic warming. Plant Cell Environ 18:93-1.04

Leemans R (1992) Modeling ecological and agricultural impacts of global change on a global scale. J Sci Ind Res 51:709-724

Mohren GMJ (1987) Simulation of forest growth, applied to Douglas fir stands in the Netherlands. Thesis, Agricultural University Wageningen

Mohren GMJ (1994) Modelling Norway spruce growth in relation to site conditions and atmospheric $\mathrm{CO}_{2}$. In: Veroustraete $F$, Ceulemans R (eds) Vegetation, modelling and

Editor: G. Esser, Gießen, Germany climate change effects. SPB Academic Publishing bv, The Hague, p 7-22

Murray MB, Cannell MGR, Smith RI (1989) Date of budburst of fifteen tree species in Britain following climatic warming. J appl Ecol 26:693-700

Murray MB, Smith RI, Leith ID, Fowler D, Lee HSJ, Friend AD, Jarvis PG (1994) Effects of elevated $\mathrm{CO}_{2}$, nutrition and climatic warming on bud phenology in Sitka spruce (Picea sitchensis) and their impact on the risk of frost damage. Tree Physiol 14:691-706

Penning de Vries FWT, Jansen DM, Ten Berge HFM, Bakema A (1989) Simulation of ecophysiological processes of growth in several annual crops. Simulation Monographs, 29, PUDOC, Wageningen

Thornley JHM (1991) A transport-resistance model of forest growth and partitioning. Ann Bot 68:211-226

Van der Voet H, Mohren GMJ (1994) An uncertainty analysis of the process-based growth model FORGRO. Forest Ecol Manage 69:157-166

Wullschleger SD (1993) Biochemical limitations to carbon assimilation in $C_{3}$ plants - a retrospective analysis of the A/C, curves from 109 species. J exp Bot 44:907-920

Ziska LH, Bunce JA (1994) increasing growth iemperdiuse reduces the stimulatory effect of elevated $\mathrm{CO}_{2}$ on photosynthesis or biomass in two perennial species. Physiol Plant 91:183-190

Manuscript first received: November 2, 1994

Revised version accepted: March 27, 1995 